\title{
Social Governance Study on Cross-border Marriages in Yunnan Border Areas: A Case Study of Jiangcheng County
}

\author{
Xia Han \\ School of Public Administration, Yunnan University of \\ Finance and Economics, \\ Kunming, P.R. China, \\ (E-mail:809141349@qq.com)
}

\author{
Yan Xiong* \\ School of Public Administration, Yunnan University of \\ Finance and Economics, \\ Kunming, P.R. China, \\ (E-mail: yxiongemail@163.com)
}

\begin{abstract}
Yunnan border areas have seen long history of cross-border marriages among its border residents and an annual growth trend of it, based on its unique geographical location and similar culture background. Brought by the situation are issues of marriage management, household register and rights and interests protection, which affect the stability of the areas. This essay takes the current cross-border marriage situation in Jiangcheng County as an entry point, analyses and explores solutions to the existing problems in cross-border marriage management through the perspective of system innovation, self-governance by village regulations and agreements and others.
\end{abstract}

Keywords-Yunnan cross-border residents; cross-border marriage; social governance; Jiangcheng

\section{INTRODUCTION}

\section{A. Background and Significance of the Study}

In border areas, the tradition of cross-border marriage and trade lives on to today for its unique geographical, ethical and cultural environment. With the constant growth of China's economy attracting out-of-border residents, the number of cross-border marriages is rising. As borders serving as China's passage for foreign exchange and a key to territorial security and social stability, it is complicated and urgent to tackle a series of practical issues brought by cross-border marriage. Based on that, study carries practical significance on how to manage cross-border immigrants triggered by cross-border marriage and how to legalize cross-border marriage for social security in these areas.

\section{B. Literature Review}

Since 1980s, cross-border marriage has gradually become a focus of scholars from different fields, and most study on it adopts the perspective of ethnology, anthropology, law and sociology. In his Study on China-Laos Cross-border Ethnicities and Ethnic Relations, Zhou Jianxin points out, by distinguishing and comparing ethnicities in China and Laos, that cross-border marriage is mainly forged by cultural identity. Li Juan probes into cross-border marriage from a legal perspective in her Legal Thinking on China-Vietnam Cross-border Marriage. Hou Xinghua believes cross-border marriage is responsible for border stability. Long Yao says in his study on the development of children of cross-border marriage couples that the children suffer certain degrees of national identity loss. This study is devoted to solutions on cross-border marriage from social governance angle.

\section{Current Cross-border Marriage Situation}

Jiangcheng County is in the south of Yunnan province, surrounded by Lixian River, Mengye River, and Manlao River, bordering Vietnam and Laos and thus nicknamed "the pivot of three countries". It is home to 125,600 people, $81.3 \%$ of which are national minorities including Hani, Yi, Dai, Yao, Lahu of 24 in total. With total land of 3,544.38 square kilometers, $99.6 \%$ of it is covered by mountains, making agriculture its primary industry.

By the end of 2014, there are 270 couples between Jiangcheng and out-of-border residents, among which marriages with Laos border residents account for 253, Vietnam for 11, and Myanmar for 6. Cross-border marriages are increasing in number annually. ${ }^{1}$

\section{CAUSES OF CROSS-BORder MARRIAGES}

\section{A. Geographical and Cultural Elements}

Jiangcheng County is uniquely located. For $183 \mathrm{~km}$ of its boundary lines, China-Vietnam boundary takes $67 \mathrm{~km}$ and China-Laos boundary takes $116 \mathrm{~km}$. In its border areas surrounded by mountains and rivers and of long boundary lines and few natural barriers, there are many convenient humble paths together with legal exit and entry passages, resulting in easy transportation and frequent contact among border residents. Besides that, despite different nationalities, most of them come from the same ethnic group sharing similar language, culture, religion and customs. The tradition of mutual contact in trade, festivals, funerals and other events lives long. This unique geographical environment and cultural background makes cross-border marriages among border residents a common practice.

\footnotetext{
${ }^{1}$ Provided by Jiangcheng County
} 


\section{B. Economic Element}

Driven by China's Reform and Opening up and the Project of Border Prosperity, China's border areas have enjoyed rapid economic growth with substantial improvement of people's livelihood. As data from Jiangcheng County shows, the per capita disposable income for urban residents in 2015 reached 22,428 yuan, an increase of $10 \%$; their rural counterpart 7,864 yuan, an increase of $15 \%$. While on the other side of its border, in countries of Vietnam and Laos, the economy is rather backward, people's livelihood is bleak, and social environment is turbulent due to incessant conflicts in places like Myanmar. The attraction of life in China to out-of-border residents prompts cross-border marriage to some extent.

\section{Disproportionate Male Female Ratio}

Compared with other places in China, border areas have rather slow economic growth, pushing many village women to seek job opportunities outside, where some of them then choose to stay. This causes disproportionate male female ratio, leaving males of marriage age too hard finding a spouse to turn their eyes to the other side of the border. ${ }^{2}$ The prevalence of cross-border marriages whether bonded by love or through arrangement is thus increasing.

\section{Social Problems IN CROSS-BORDER MARRIAGES}

\section{A. Low Marriage Register Rate with Many De Facto Marriages}

Data shows that by the end of 2014 , only 124 out of 253 couples between Jiangcheng and Laos have registered in civil affairs department with 129 remain unregistered; none of 11 Jiangcheng-Vietnam couples and 1 out of 6 JiangchengMyanmar couples have registered. The low marriage register rate is mainly due to the following reasons.

\section{1) Excessive cross-border marriage register procedure}

The cross-border marriage register procedure is complicated, time-consuming and costly due to different policies on both sides of the border. As for Jiangcheng County, except Lao border residents, Vietnam border residents are required to go through procedure in provincial register organs of their own country before register in China. Coming from families in dire need, most of these couples cannot afford certificate and transportation fees. Their illiteracy and confined life to only local villages without even going to the county makes it quite a hardship to go to provincial register organs. More than that, marriage register usually requires such material as identity certificate of original nation and exit and entry document, which those out-of-border residents are unable to provide.

\section{2) Lack of legal consciousness on marriage register}

For border residents, inadequate basic education and publicity and long residence in mountain areas reduce them to low levels of education and scanty legal knowledge, believing marriage to be living together after a wedding ceremony as local rituals go, without a must to carry marriage register. With pervasive de facto marriages, many residents are unclear of cross-border marriage register procedure limited by their education level. Besides that, almost without stepping out of their villages, these residents think it unnecessary to register their marriage.

\section{B. Low Settlement Rate}

Despite their de facto marriages, many out-of-border residents are hard to be settled in China for their lack of legal marriage register, identity, marriage certificate and birth permit, worsened by possible lack of original nationality before marriage. According to relevant stipulations of the Ministry of Public Police, Chinese nationality procedure is rather complicated and difficult for border residents because of their language, culture, financial status and legal attainment. Absent legal identity poses an obstacle to their establishment. For Chinese citizens' basic activities of accommodation, travel, employment and business cannot go without identity card, outof-border residents after marriage can only engage in basic agricultural activities in villages, ruling out the possibility to be employed elsewhere.

\section{Unprotected Social Rights and Interests}

Without Chinese nationality, those out-of-border residents after marriage are unqualified to national policies of benefiting farmers, mountain land distribution, as well as new rural medical system, medical aid and basic social insurance for low income and old age. Tight financial situation and deprivation of an array of beneficial policies leave no room to improve for these families, bringing unrest to border areas to some extent.

\section{Limited Settlement and Education for Children of Cross- border Marriage Families}

For cross-border marriage families, they reside without marriage certificate for its illegal feature, birth medical aid and birth certificate because of their absence from formal hospitals for child delivery. For that their children are unable to be settled. When finishing nine-year compulsory education, they are forbidden in access to higher levels of education. And for lacking legal identity, they face employment issue, and are turned away from beneficial policies in land, medical care and others, which is a heavy limitation to their personal life and development.

\section{Social Governance Solutions TO CROSS-BORDER MARRIAGES AMONG BORDER RESIDENTS}

\section{A. Strengthening Legal Awareness through Publicity}

Due to border residents' almost illiteracy in relevant national laws and regulations on marriage register and weak sense of national border, governments and relevant organs in border areas should promote legal publicity on some policies and regulations to make aware laws and regulations on marriage register among border residents, through accessible ways of publicity photo exhibitions, law-themed operas and 
cultural performances. Such is the way for border residents to realize that only marriage registered through formal procedure is legal.

\section{B. Giving a Full Play to Village Regulations and Agreements}

While devoting to improve relevant laws and regulations, local grassroots organizations on village and town level should act as regulators and administers to standardize cross-border marriages with the participation of locals. By using abundant social resources and powers and conventional village regulations and agreements, a joint mechanism between governments and grassroots organizations is set up to aid the management of border residents of cross-border marriage and regulate the behaviors of those families.

\section{Remedies to the Existing "De Facto Chinese Citizens"}

For those border residents of cross-border marriage with their long residence within China and status as "de facto Chinese citizens", they can be granted legal identity with certain conditions fulfilled. For example, legal identity is granted to those who have been married into China with a spouse of Chinese nationality for entire 5 years and reside in China for over 5 consecutive years without law breaking behaviors. Governments can consider simplifying certificate procedure as a faster access to increase legal register rate based on border residents' rather low levels of education level and their difficulty in submitting relevant material.

\section{Improving Laws and Regulations, Enhancing Bilateral Cooperation}

With two nations involved in cross-border marriages, unilateral efforts are insufficient in solving the issue. China should strengthen communication and consultation with governments from neighboring countries, clarify due responsibilities of relevant organs from both sides, build an effective platform for cross-border marriage affairs and improve the existing laws and regulations through cooperation and mutual understanding of them. By targeted improvement on laws and regulations on cross-border marriages and further simplification of register procedures, governments can provide practical legal protection and easy service in terms of crossborder marriages.

\section{E. Adopting Cross-border Marriage Register Record System}

To cope with the low register rate, China is able to innovate its demographic management mode by adopting register record system. Under this system, out-of-border residents of crossborder marriage can be recorded for their basic information before their household and marriage register, which is a guarantee to control on out-of-border residents and stability of border areas.

\section{F. Delegating the Cross-border Marriage Register Authority to Local Level}

Yunnan border areas suffer from transport hurdles, low levels of education among border residents and rather backward economy. To manage cross-border marriages for the good of the locals, cross-border marriage register organs can be set up just in border areas, or civil affairs department from upper level mobilizes its service to specific villages. Furthermore, the authority to register cross-border marriages can be delegated to civil affairs department on village and town level, in an attempt to raise register rate, benefit the locals, reduce costs, and aid governments in controlling out-of-border residents.

\section{CONCLUSION}

With the launching of Bridgehead Strategy, the number of cross-border marriages between China and its neighboring Laos, Vietnam and Myanmar are rising annually. Followed by it are issues worthy of attention on household and marriage register, social security, children education and management. These issues should be solved from social governance perspective by extending publicity, improving relevant laws and regulations, strengthening the role of local organizations, and putting people first. Social problems triggered by crossborder marriages will be practically solved to safeguard stability and development of border areas.

\section{ACKNOWLEDGMENT}

Sincere gratitude should be given to my mentor Professor Yan Xiong, who through his busy schedule of teaching and research work, made his time to instruct my paper and presented me with material of his own collection for reference, which proved to better me a lot. From topic selection to its final completeness, the paper has been under my mentor' $\mathrm{s}$ attentive instruction. Hereby I would like to express my heartfelt gratitude and good wishes to him.

Acknowledgement should also be given to my parents, for their support and encouragement in my school time, and their care and love for all those years!

\section{REFERENCES}

[1] Hou Ying, Study on Social Governance Solutions to Cross-border Marriages among Yunnan-Vietnam Border Residents- Case Study on Jinping County on the Yunnan-Vietnam Border [J]. Heihe Journal, 2015 , (10).(In Chinese)

[2] Li Xiaohui, Luo Chunmei. Initial Exploration on the Management of Mixed Marriage among China-Myanmar Border Residents [J]. Journal of the Staff and Worker' s University, 2012, (3).(In Chinese)

[3] Lu Haifa. Management on Cross-border Mixed Marriage Immigrants Challenges and Solutions [J]. Journal of Southwest University of Nationalities (Social Science), 2015, (3).(In Chinese)

[4] Wu xingzhi.Research of Cross-border Ethnic Intercourse between China and Vietnam and Governance of Borderland Community-A case of Study of Hekou,Jinping County in Yunnan[J].Journal of Qinghai Normal University(Philosophy and Social Sciences),2015,(2).(In Chinese)

[5] Zhang Aihua. Brief Analysis on Illegal Residence in Yunnan-Myanmar Border Areas-Perspective from Entry Marriage among Dehong Border Residents [J]. Journal of Guangxin Police Academy, 2013, (6).(In Chinese)

[6] Zhao Shujuan.A Survey of Cross-Border Marriages-A Case Study of Sino-Burmese Border in Yunnan[J].Journal of Chuxiong Normal University,2011,(10).(In Chinese) 